\title{
Desempenho do quiabeiro consorciado com adubos verdes eretos de porte baixo em dois sistemas de cultivo
}

\author{
Sebastião Wilson Tivelli ${ }^{1}$; Cristiaini Kano ${ }^{2}$; Luis Felipe V Purquerio ${ }^{3}$; Elaine B Wutke ${ }^{3}$;ssáo Ishimura ${ }^{1}$ \\ ${ }^{1}$ APTA/DDD, UPD São Roque, Av. Três de maio 900, 18133-445 São Roque-SP; tivelli@apta.sp.gov.br; issao@apta.sp.gov.br; ${ }^{2} E m-$ \\ brapa Amazônia Ocidental, C. Postal 319,69010-970 Manaus-AM; cristiaini.kano@embrapa.br; ${ }^{3}$ APTA, IAC, C. Postal 28, 13012-970 \\ Campinas-SP; felipe@iac.sp.gov.br; ebwutke@iac.sp.gov.br
}

\section{RESUMO}

Com o objetivo de avaliar o cultivo intercalar de adubos verdes eretos e de porte baixo na cultura do quiabeiro, foram conduzidos dois experimentos, sendo um em cultivo convencional em Monte Alegre do Sul e outro em cultivo orgânico em São Roque-SP, de fevereiro a julho de 2008 e de dezembro de 2008 a junho de 2009 , respectivamente. Utilizou-se o delineamento de blocos casualizados com cinco repetições e cinco tratamentos, constando de quiabeiro em cultivo "solteiro" e consorciado com uma ou duas linhas de mucuna-anã (Mucuna deeringiana) e de crotalária-espectábilis (Crotalaria spectabilis) nas entrelinhas. No cultivo orgânico, dois novos tratamentos foram adicionados ao experimento para avaliar os adubos verdes em cultivo solteiro. No quiabeiro avaliou-se a produção $\left(\mathrm{g}_{\text {planta }} \mathrm{p}^{-1}\right)$ e número de frutos por planta, comprimento e diâmetro dos frutos e altura média do dossel em diferentes épocas após a semeadura. Nos adubos verdes avaliaram-se altura média das plantas e produtividade de massa fresca. A eficiência do consórcio foi mensurada por meio da relação de área equivalente (RAE). A produção média do quiabeiro por planta foi de 190,9 e 582,0 g planta-1 $^{-1}$, respectivamente, no sistema convencional e orgânico. A RAE foi de 1,5 e 1,6 no consórcio do quiabeiro com duas linhas de mucuna-anã e crotalária-espectábilis, respecticamente. Verificou-se viabilidade agronômica da adoção do cultivo intercalar pelo agricultor familiar de quiabeiro, especificamente com duas linhas dos adubos verdes de porte ereto e baixo.

Palavras-chave: Abelmoschus esculentus, Mucuna deeringiana, Crotalaria spectabilis, produção, manejo do solo, sustentabilidade.

\begin{abstract}
Okra performance intercropped with small size and erect green manure in two production systems

To evaluate the agronomic viability of the intercropping okra crop (Abelmoschus esculentus) with small size and erect green manuring species Mucuna deeringiana and Crotalaria spectabilis, two experiments were carried out, one in conventional system at Monte Alegre do Sul, São Paulo state, Brazil, from February to July 2008 and one in an organic system at São Roque, São Paulo state, Brazil, from December 2008 to June 2009. The experimental design was randomized complete blocks, with five treatments and five replications. The five treatments were constituted by okra monoculture and okra intercropped with one or two lines of $M$. deeringiana and one or two lines of C.spectabilis in the seeded at the same time of the okra crop. In organic farming two new treatments were added to the experiment to evaluate the green manures in single cropping. Production, number of fruits per plant, fruit length and diameter and plant height were evaluated in okra plants and plant height and fresh matter weight were determined in the green manuring plants at different periods after seeding.. The evaluation of the efficiency of the consortium was measured by the ratio of area equivalent (RAE). Average yield per okra plant was 190.9 and 582.0 g plant $^{-1}$, respectively, under conventional and organic cropping. The RAE was 1.5 and 1.6 in the consortium of okra with two rows of $M$. deeringiana and Crotalaria spectabilis, respectively. Intercropping erect short green manuring species with okra is agronomically viable and can be used by family farmers without interference with the yield of okra crop.
\end{abstract}

Keywords: Abelmoschus esculentus, Mucuna deeringiana, Crotalaria spectabilis, production, soil management, sustainability.

(Recebido para publicação em 12 de junho de 2012; aceito em 14 de junho de 2013) (Received on June 12, 2012; accepted on June 14, 2013)

$\mathrm{O}$ fruto imaturo do quiabeiro é uma hortaliça componente de pratos típicos regionais como o caruru na Bahia e o frango com quiabo em Minas Gerais (Melo, 2007). É cultivado em 28.367 propriedades agrícolas em todo o Brasil, porém, com reduzido nível tecnológico. De acordo com o Censo Agropecuário, não se utiliza irrigação em cerca de $43,8 \%$ dessas propriedades ou qualquer tipo de adubação em $32,0 \%$. O adubo mineral é utilizado em apenas $15,9 \%$ dos estabelecimentos recenseados, enquanto que o adubo orgânico é exclusivamente adotado por $32,7 \%$ dos agricultores (IBGE, 2006).

Essa realidade não é diferente daquela constatada no estado de São Paulo, em que se cultivam 2.446 ha com o quiabeiro, mais significativamente nos municípios de Araçatuba, Capela do Alto, Piacatu e Promissão (São Paulo, 2008) por agricultores familiares. A produtividade média da cultura em 2006 no estado foi de $13.515 \mathrm{~kg} \mathrm{ha}^{-1}$ (Camargo et al., 2008).

Pelas características do cultivo, no estado de São Paulo, a cultura é considerada promotora do desenvolvimento econômico e social de municípios e regiões devido à geração de renda e emprego. O espaçamento largo (de até 1,2 $\mathrm{m}$ ) entre as linhas desta cultura favorece o surgimento de plantas espontâneas. Essas devem ser manejadas para não comprometer a produção do quiabeiro; 
para isso é demandado tempo de serviço dos membros da família ou de pessoa contratada. Além disto, o solo é mantido muitas vezes descoberto nas entrelinhas da cultura, sendo favorecida a erosão e desfavorecida a população microbiana benéfica do solo pela constante alteração das condições de temperatura e umidade no mesmo.

O cultivo do quiabo pela agricultura familiar em São Paulo é realizado em pequenas áreas, o que normalmente não é encorajador à realização da rotação de culturas pelos agricultores, particularmente com adubos verdes. $\mathrm{Na}$ visão imediatista dos agricultores, na área com adubo verde não será gerada renda para a família durante um determinado período, mas continuará a demandar por atenção. Além disso, os agricultores, em geral, não mensuram os benefícios com a adubação verde, como por exemplo, a possibilidade de substituição parcial ou total da adubação nitrogenada na cultura da hortaliça subsequente ou reduzir-se a necessidade de fertilização em diversas culturas em até 50\% (Tivelli et al., 2010; Wutke et al., 2010).

A utilização da adubação verde pelos agricultores familiares é também limitada pela inexistência ou escassez de assistência técnica, sem a qual as informações sobre as espécies mais indicadas para cada cultura em determinada região não são devidamente disponibilizadas aos agricultores (Monegat, 1991). Kano et al. (2010) consideram que a reduzida adoção da adubação verde, na horticultura comercial, é devido à intensa programação semanal de plantio/ transplante, tratos culturais e colheitas, sendo dificultada a programação dos agricultores para o cultivo do adubo verde em áreas de pousio ou de rotação de culturas.

Há, no entanto, diversas maneiras de fazer a adubação verde. Quando o sistema rotacional não é interessante por alguma razão, tem-se a opção do cultivo consorciado, com vantagens adicionais como o aporte de nitrogênio e o controle de plantas espontâneas (César et al., 2007). Com a inclusão da adubação verde no sistema produtivo das hortaliças, além da redução no aporte de fertilizantes para as mesmas, pode-se obter aumento da eficiência do uso da água no cultivo de hortaliças pela cobertura morta proporcionada pelos adubos verdes (Tivelli et al., 2010).

Em Tianguá-CE, em consórcio do quiabeiro com uma linha de crotaláriaespectábilis (Crotalaria spectabilis), em área infestada naturalmente por nematoide Meloidogyne incógnita, após sucessivos cultivos de tomate e pimentão, a altura média de plantas, o número e a massa média de frutos foram superiores aos do quiabeiro em cultivo solteiro (Andrade \& Ponte, 1999). Os autores, contudo, não relataram o manejo na cultura principal do quiabeiro para prevenção de competição com a cultura do adubo verde.

Em consórcio de quiabeiro com crotalária-júncea (Crotaria juncea) semeada aos 30 dias após o transplante das mudas da hortaliça e cujas plantas foram cortadas aos 90 dias e deixadas sobre a superfície do solo como cobertura morta, foram determinados ganhos de $11 \%$ ao quiabeiro, em experimento desenvolvido em Seropédica-RJ (Ribas et al., 2003).

O cultivo consorciado de hortaliças com adubos verdes vem sendo recentemente estudado em outras hortaliças além do quiabeiro. Em Seropédica-RJ, o cultivo de pimentão foi consorciado com duas linhas de crotalária-júncea nas entrelinhas entre 27 e 45 dias após o transplante das mudas da hortaliça. Após o período de convivência simultânea, a crotalária foi cortada e as plantas mantidas como cobertura morta junto às plantas de pimentão. Com a crotalária cortada aos 45 dias após o transplante do pimentão foram produzidas 7,2 $\mathrm{t} \mathrm{ha}^{-1} \mathrm{de}$ massa aérea fresca e fornecidos $74,4 \mathrm{~kg}$ $\mathrm{ha}^{-1}$ de N. A produtividade de pimentão foi consequentemente favorecida no cultivo consorciado ( $1,6 \%$ de acréscimo), apesar de não haver incremento na massa média dos frutos (César et al., 2007).

O consórcio de culturas pode ser uma alternativa para que agricultores familiares incorporem a prática da adubação verde na rotina das atividades produtivas quando o sistema rotacional de culturas for inviável economicamente. Em virtude do exposto, o objetivo desse trabalho foi avaliar o consórcio de adubos verdes eretos e de porte baixo no cultivo do quiabeiro, em cultivos convencional e orgânico.

\section{MATERIAL E MÉTODOS}

Os experimentos foram conduzidos em áreas experimentais da Agência Paulista de Tecnologia dos Agronegócios, em Monte Alegre do Sul-SP (22 40'55"S; 4640'50"O, $900 \mathrm{~m}$ de altitude) e na Unidade de Pesquisa e Desenvolvimento São Roque, em São Roque-SP (2331'02'S; 4707'45'O; $830 \mathrm{~m}$ de altitude), de $1^{\circ}$ de fevereiro a 21 de julho de 2008 em Monte Alegre do Sul e de 17 de dezembro de 2008 a 24 de junho de 2009 em São Roque. Utilizou-se a cultivar Santa Cruz 47, sendo cultivada em sistema convencional e orgânico, respectivamente.

Utilizou-se nos experimentos o delineamento de blocos casualizados com cinco tratamentos, a saber: T1: testemunha, correspondente ao cultivo solteiro do quiabeiro; T2: quiabeiro consorciado com uma linha de mucuna-anã (Mucuna deeringiana); T3: quiabeiro consorciado com duas linhas de mucuna-anã; T4: quiabeiro consorciado com uma linha de crotalária-espectábilis (Crotalaria spectabilis) e T5: quiabeiro consorciado com duas linhas de crotalária-espectábilis; e cinco repetições. No experimento realizado em São Roque, dois outros tratamentos foram adicionados para avaliar a produção de biomassa dos adubos verdes em cultivo solteiro.

Os resultados das análises químicas iniciais do solo foram: $\mathrm{pH}\left(\mathrm{CaCl}_{2}\right) 5,8$ e 6,$0 ; \mathrm{P}_{\text {resina }} 32$ e $67 \mathrm{mg} \mathrm{dm}^{-3}$; matéria orgânica 21 e $35 \mathrm{~g} \mathrm{dm}^{-3}$; V\% 70 e $81 \%$; $\mathrm{H}+\mathrm{Al} 20$ e $19 \mathrm{mmol}_{\mathrm{c}} \mathrm{dm}^{-3}$; K 2,6 e 7,7 mmol dm ${ }^{-3}$; Ca 31 e $50 \mathrm{mmol} \mathrm{dm}^{-3}$; $\mathrm{Mg} 13$ e $20 \mathrm{mmol}_{\mathrm{c}} \mathrm{dm}^{-3}$; SB 46,6 e 78 $\mathrm{mmol}_{\mathrm{c}} \mathrm{dm}^{-3}$ e CTC 66,8 e $97 \mathrm{mmol}_{\mathrm{c}} \mathrm{dm}^{-3}$, respectivamente para Monte Alegre do Sul e São Roque. Para o experimento no sistema convencional, na adubação de plantio foi utilizado o equivalente a $180 \mathrm{~kg} \mathrm{ha}^{-1}$ de $\mathrm{P}_{2} \mathrm{O}_{5}$ e a $120 \mathrm{~kg} \mathrm{ha}^{-1}$ de $\mathrm{K}_{2} \mathrm{O}$. Na adubação de cobertura foram aplicados $120 \mathrm{~kg} \mathrm{ha}^{-1}$ de $\mathrm{N}$ e $90 \mathrm{~kg} \mathrm{ha}^{-1}$ de $\mathrm{K}_{2} \mathrm{O}$, distribuídos em três aplicações, aos 20, 40 e 60 dias após a emergência do quiabeiro, segundo recomendação para o estado de São Paulo (Trani et al., 1997). Com base nesta mesma recomendação, na adubação de plantio 
do quiabeiro no sistema orgânico, foram utilizados $10 \mathrm{~L}$ de composto orgânico por metro linear, aplicados manualmente em sulcos de $0,15 \mathrm{~m}$ de profundidade, uma semana antes do plantio. A composição do composto, à base de esterco de cavalo, era: pH 6,7; umidade 32,4\%; 42,9 g de $\mathrm{C} \mathrm{kg}^{-1}$; 2,9 g de $\mathrm{N} \mathrm{kg}^{-1}$; 2,5 g de $\mathrm{P} \mathrm{kg}^{-1} ; 2,2 \mathrm{~g}$ de $\mathrm{K} \mathrm{kg}^{-1}$; 4,3 g de $\mathrm{Ca} \mathrm{kg}^{-1}$; 1,3 g de $\mathrm{Mg} \mathrm{kg}^{-1} ; 1,1 \mathrm{~g}^{\mathrm{de} \mathrm{S} \mathrm{kg}}{ }^{-1} ; 5,0 \mathrm{mg}$ de $\mathrm{B} \mathrm{kg}{ }^{-1} ; 13,6$ mg de $\mathrm{Cu} \mathrm{kg}^{-1} ; 20.120$ mg de Fe kg-1; 229 mg de $\mathrm{Mn} \mathrm{kg}^{-1} ; 63,5$ mg de $\mathrm{Zn} \mathrm{kg}^{-1}$; e relação $\mathrm{C} / \mathrm{N}$ de 14,8 . Devido ao desenvolvimento do quiabeiro e à quantidade de composto colocada no plantio, não se realizou adubação de cobertura neste experimento.

Os adubos verdes foram semeados no mesmo dia do quiabeiro, exceto para a crotalária no sistema convencional que precisou ser ressemeada aos 33 dias após a semeadura (DAS) do quiabeiro em razão da reduzida emergência constatada anteriormente. Nos tratamentos consorciados, o adubo verde foi semeado nas entrelinhas do quiabeiro, alternando-se uma entrelinha com adubo verde e outra entrelinha sem adubo verde na parcela. As densidades de semeadura foram sete a doze e 16 a 20 sementes por metro, respectivamente para a mucuna-anã e crotalária, em ambos os experimentos. Nos tratamentos T2 e T4, a única linha do adubo verde foi semeada exatamente no centro da entrelinha do quiabeiro e, nos tratamentos T3 e T5, as linhas duplas dos adubos verdes foram estabelecidas a partir do centro da entrelinha do quiabeiro e espaçadas $0,4 \mathrm{~m}$ e $0,5 \mathrm{~m}$ entre si, respectivamente para a mucuna-anã e a crotalária. Cada parcela foi composta de quatro linhas de quiabeiro com 5,0 m de comprimento. O espaçamento do quiabeiro foi de 1,2 x 0,3 m, deixando-se uma planta por cova. $\mathrm{Na}$ parcela, a área útil foi composta por dez plantas competitivas de quiabeiro das duas linhas centrais. Isto foi necessário devido à possibilidade de aparecimento ou não de ramificações laterais no quiabeiro, com eventual comprometimento dos resultados de produção por planta.

O manejo das plantas espontâneas e da irrigação, por aspersão, foi realizado nos dois experimentos de acordo com as necessidades da cultura do quiabeiro. No cultivo convencional foram realizadas pulverizações com leite de vaca cru na concentração de $10 \%$ e com produto à base de dióxido de cloro, visando-se o controle de oídio (Erysiphe cichoracearum); no cultivo orgânico não houve necessidade de controle de pragas e doenças.

Foram realizadas de uma a três colheitas de frutos por semana, tendo início aos 82 e 79 dias após o plantio (DAP) e finalizando aos 172 e 189 DAP, nos sistemas convencional e orgânico, respectivamente. Avaliou-se a produção por planta $\left(\mathrm{g}_{\text {planta }}{ }^{-1}\right)$, número de frutos por planta, comprimento e diâmetro dos frutos, em centímetros, e a altura das plantas, em centímetros, do quiabeiro aos 81 e 70; 110 e 100; 172 e 180 DAP, respectivamente nos sistemas convencional e orgânico. Nas plantas no sistema convencional avaliou-se ainda a produção comercial e o número de frutos comerciais. No sistema convencional a altura média dos adubos verdes foi determinada no pleno florescimento da mucuna-anã (75 DAS) e da crotalária (72 DAS), e no final da colheita do quiabeiro (172 DAS). No sistema orgânico a altura dos adubos verdes foi mensurada aos 70 DAS e estes foram roçados e deixados para cobertura morta no local aos 83 DAP. Foi avaliada a quantidade de massa fresca dos adubos verdes em duas amostragens de $0,25 \mathrm{~m}^{2}$ por parcela, dados estes transformados em $\mathrm{t} \mathrm{ha}^{-1}$. Ainda no sistema orgânico foi mensurada a relação de área equivalente (RAE) para avaliar a eficiência do consórcio em relação ao cultivo solteiro do quiabeiro e dos adubos verdes (Cecílio Filho \& May, 2002). A RAE foi obtida pela expressão $\mathrm{RAE}=\left(\mathrm{C}_{\mathrm{q}} \mathrm{S}_{\mathrm{q}}^{-1}\right)+\left(\mathrm{C}_{\mathrm{av}} \mathrm{S}_{\mathrm{av}}{ }^{-1}\right)$ em que, $\mathrm{C}_{\mathrm{q}} \mathrm{e}$ $\mathrm{C}_{\mathrm{av}}$ são, respectivamente, a produção por planta do quiabeiro (g planta ${ }^{-1}$ ) e a produtividade de massa fresca dos adubos verdes $\left(\mathrm{t} \mathrm{ha}^{-1}\right)$ consorciados, enquanto $\mathrm{S}_{\mathrm{q}}$ e $\mathrm{S}_{\mathrm{av}}$ são, respectivamente, a produção por planta do quiabeiro (g planta $\left.{ }^{-1}\right)$ e a produtividade de massa fresca dos adubos verdes ( $\mathrm{t} \mathrm{ha} \mathrm{h}^{-1}$ ) no cultivo solteiro. A diferença na avaliação de alguns parâmetros em ambos os experimentos não está relacionada ao sistema de cultivo, mas sim pela apropriação dos resultados do primeiro experimento (convencional) com a finalidade de desenvolver uma tecnologia adequada aos agricultores familiares no estado de São Paulo.

Os dados de produção e caracterização do quiabeiro, bem como os dos adubos verdes, foram submetidos à análise de variância pelo teste $\mathrm{F}$ e, em caso de efeito significativo para tratamentos, ao teste de Tukey a 5\% de probabilidade. Os sistemas foram comparados pelo fatorial consórcio $\mathrm{x}$ monocultivo Os dados de altura do quiabeiro e dos adubos verdes foram analisados pela estatística descritiva. Não se realizou a análise conjunta dos experimentos em razão das diferenças no desenvolvimento das plantas nos experimentos.

\section{RESULTADOS E DISCUSSÃO}

Não foi verificada diferença estatística significativa entre os tratamentos para a produção por planta nas condições em que foi realizado o experimento no sistema convencional em Monte Alegre do Sul-SP (Tabela 1). No sistema orgânico, em São Roque-SP, constatou-se superioridade estatística nessa mesma característica apenas no tratamento do consórcio com uma linha de crotalária em relação ao consórcio com uma linha de mucuna-anã (Tabela 2). Essas produções, contudo, foram estatisticamente semelhantes à produção por planta obtida nos quiabeiros em cultivo solteiro (testemunha) no sistema orgânico.

No consórcio do quiabeiro com a mucuna-anã e crotalária-espectábilis, semeados no mesmo dia, evidencia-se a possibilidade de adoção desta tecnologia pelos agricultores familiares sem prejuízo à produção da cultura principal. Ao se adotar a prática de consórcio ao invés do cultivo rotacionado, poderá ser incrementada a biodiversidade no cultivo da hortaliça, obtendo-se, ainda, um efeito positivo de proteção do solo, como preconizado em Wutke et al. (2007, 2010) e Tivelli et al. (2010). Ganhos expressivos de produtividade em hortaliças, como os constatados nas culturas de quiabo (Ribas et al., 2003) e de pimentão (César et al., 2007), não foram determinados nos experimentos de Monte Alegre do Sul e São Roque. Isso pode estar relacionado ao nível de fertilidade dos solos, inicialmente mais elevado, particularmente quanto ao teor 
Tabela 1. Produção média total (PT), número total de frutos por planta (NTF), número de frutos comerciais por planta (NFC), comprimento (CFC) e diâmetro (DFC) dos frutos comerciais de quiabeiro cultivar Santa Cruz 47 em distintos tratamentos de consórcio, sob manejo convencional [average total fruits production (PT), total number of fruits per plant (NTF), number of marketable fruits per plant (NFC), length (CFC) and diameter (DFC) of marketable fruits of okra cultivar Santa Cruz 47 at different intercropping treatments, under conventional management]. Monte Alegre do Sul, APTA, 2008.

\begin{tabular}{lccccc}
\hline \multirow{2}{*}{ Tratamento } & $\begin{array}{c}\text { PT } \\
\text { (g planta }^{-1} \text { ) }\end{array}$ & NTF & NFC & CFC & DFC \\
\cline { 5 - 6 } & $155,3 \mathrm{a}$ & $13,9 \mathrm{a}$ & $12,7 \mathrm{a}$ & $10,2 \mathrm{a}$ & $1,3 \mathrm{a}$ \\
T1: testemunha (quiabeiro solteiro) & $189,4 \mathrm{a}$ & $17,0 \mathrm{a}$ & $15,8 \mathrm{a}$ & $10,0 \mathrm{a}$ & $1,3 \mathrm{a}$ \\
T2: quiabeiro + 1 linha de mucuna-anã & $217,0 \mathrm{a}$ & $18,7 \mathrm{a}$ & $17,0 \mathrm{a}$ & $10,2 \mathrm{a}$ & $1,3 \mathrm{a}$ \\
T3: quiabeiro + 2 linhas de mucuna-anã & $213,9 \mathrm{a}$ & $18,8 \mathrm{a}$ & $17,6 \mathrm{a}$ & $10,1 \mathrm{a}$ & $1,3 \mathrm{a}$ \\
T4: quiabeiro + 1 linha de crotalária-espectábilis & $178,7 \mathrm{a}$ & $15,8 \mathrm{a}$ & $13,9 \mathrm{a}$ & $10,0 \mathrm{a}$ & $1,3 \mathrm{a}$ \\
T5: quiabeiro + 2 linhas de crotalária-espectábilis & 21,1 & 22,0 & 23,1 & 2,9 & 3,1 \\
\hline CV (\%)
\end{tabular}

Médias seguidas pela mesma letra na coluna não são diferentes estatisticamente entre si pelo teste de Tukey a 5\% de probabilidade (means followed by same letters in the column are not different by the Tukey test, $\mathrm{p}>0.05$ ).

Tabela 2. Produção média e número de frutos por planta, comprimento (CF) e diâmetro (DF) dos frutos do quiabeiro cultivar Santa Cruz 47, e massa fresca (MF) dos adubos verdes obtidos em cada tratamento, sob manejo orgânico, e os contrastes [average of fruits production and number of fruits per plant, length (CF) and diameter (DF) of okra fruits cultivar Santa Cruz 47, and green manuring fresh weight (MF), under organic management, and the contrasts]. São Roque, UPD São Roque, 2009.

\begin{tabular}{lccccc}
\hline Tratamento & $\begin{array}{c}\text { Produção } \\
\left.\text { (g planta }^{-1}\right)\end{array}$ & $\begin{array}{c}\text { Número de } \\
\text { frutos }\end{array}$ & $\begin{array}{c}\text { CF } \\
(\mathbf{c m})\end{array}$ & $\begin{array}{c}\text { DF } \\
(\mathbf{c m})\end{array}$ & $\begin{array}{c}\text { MF } \\
\left(\mathbf{t} \mathbf{h a}^{-1}\right)\end{array}$ \\
\hline T1: testemunha (quiabeiro solteiro) & $555,4 \mathrm{ab}$ & $22,1 \mathrm{bc}$ & $19,0 \mathrm{~b}$ & $2,4 \mathrm{a}$ & - \\
T2: quiabeiro + 1 linha de mucuna-anã & $467,6 \mathrm{~b}$ & $20,4 \mathrm{c}$ & $17,5 \mathrm{c}$ & $2,4 \mathrm{a}$ & $12,2 \mathrm{ab}$ \\
T3: quiabeiro + 2 linhas de mucuna-anã & $611,7 \mathrm{ab}$ & $24,5 \mathrm{abc}$ & $19,8 \mathrm{a}$ & $2,5 \mathrm{a}$ & $17,8 \mathrm{a}$ \\
T4: quiabeiro + 1 linha de crotalária-espectábilis & $662,4 \mathrm{a}$ & $29,0 \mathrm{a}$ & $17,3 \mathrm{c}$ & $2,4 \mathrm{a}$ & $7,3 \mathrm{~b}$ \\
T5: quiabeiro + 2 linhas de crotalária-espectábilis & $612,7 \mathrm{ab}$ & $27,2 \mathrm{ab}$ & $16,2 \mathrm{~d}$ & $2,2 \mathrm{a}$ & $15,8 \mathrm{a}$ \\
\hline CV (\%) & 16,2 & 10,9 & 2,0 & 7,0 & 11,9 \\
\hline Contrastes (diferenças de médias) & & & & & \\
\hline Q solteiro x consorciado & $-33,2^{\text {ns }}$ & $-3,2^{*}$ & $1,3^{* *}$ & $0,0^{\text {ns }}$ \\
Q uma linha x Q duas linhas (mucuna-anã) & $-144,1^{*}$ & $-4,1^{*}$ & $-2,3^{* *}$ & $-0,1^{\text {ns }}$ & \\
Q uma linha x Q duas linhas (crotalária) & $49,7^{\text {ns }}$ & $1,8^{\text {ns }}$ & $1,1^{* *}$ & $0,2^{\text {ns }}$ & \\
Mucuna-anã x crotalária & $-97,9^{*}$ & $-5,6^{* *}$ & $1,9^{* *}$ & $0,15^{\text {ns }}$ \\
\hline
\end{tabular}

Médias seguidas pela mesma letra na coluna não são diferentes estatisticamente entre si pelo teste de Tukey a 5\% de probabilidade; *Sig-

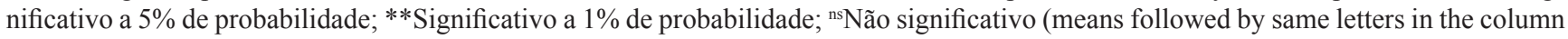

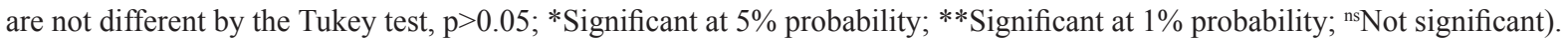

normal de matéria orgânica.

A produção comercial por planta no experimento convencional em Monte Alegre do Sul foi concordante com o resultado da produção total, ou seja, não foi diferente em função dos tratamentos (dados não apresentados). Pode ter havido influência positiva da frequência das colheitas neste experimento para a qualidade dos frutos, já que apenas 6,4 a $12,0 \%$ dos frutos foram classificados como não comerciais. Em razão da apropriação deste resultado e das características do mercado local em São Roque, os frutos no experimento orgânico não foram classificados em comerciais e não comerciais.

No sistema convencional de produção do quiabeiro, o número de frutos por planta, bem como seu comprimento e diâmetro médio não foram estatisticamente diferentes entre os tratamentos, sendo de $10,1 \mathrm{~cm}$ o comprimento e $1,3 \mathrm{~cm}$ o diâmetro médio dos frutos (Tabela 1). Resultados semelhantes foram determinados por Ribas et al. (2003), os quais, em experimento desenvolvido com quiabeiro consorciado com crotalária-júncea, não apuraram diferenças na produtividade de frutos no consórcio com duas e três fileiras do adubo verde na entrelinha (30,3 e 30,8 $\mathrm{t} \mathrm{ha}^{-1}$, respectivamente), entre 30 e 120 dias após o transplante das mudas do quiabeiro.

Por outro lado, no cultivo em sistema orgânico, o número de frutos por planta foi certamente influenciado pelos tratamentos avaliados. Foram produzidos mais frutos no quiabeiro consorciado com uma linha de crotalária, tratamento superior e distinto apenas da testemunha com quiabeiro em cultivo solteiro e daquele consorciado com uma linha de mucuna-anã; estes dois últimos tratamentos não foram significativamente diferentes entre si (Tabela 2).

No experimento de São Roque, as 
diferenças determinadas no comprimento dos frutos foi um resultado não esperado, visto que todos os frutos foram colhidos à medida que foi atingido o tamanho comercial para os padrões das feiras livres desse município. Por outro lado, não se verificou diferença estatística significativa para o diâmetro dos frutos de quiabo devido aos tratamentos (Tabela 2). Este resultado era esperado, visto que os tratamentos foram aplicados na mesma cultivar de quiabo, a cv. Santa Cruz 47.

No cultivo convencional, o pleno florescimento das plantas de mucuna-anã foi constatado aos 75 DAS, ocasião em que também foi avaliada a altura média das plantas, cujos valores foram entre 36,6 e $37,2 \mathrm{~cm}$. Independentemente do número de linhas semeadas nas entrelinhas do quiabeiro esses valores foram muito menores do que os 65,7 $\mathrm{cm}$ de altura determinados nesse mesmo adubo verde, aos 70 DAS no cultivo orgânico. Em uma escala menor, essa tendência também foi verificada na crotalária, cujo pleno florescimento foi determinado aos 72 DAS. As médias de altura da crotalária em uma ou duas linhas semeadas nas entrelinhas do quiabeiro foram respectivamente 115,2 e $115,9 \mathrm{~cm}$, no cultivo convencional. No cultivo orgânico o florescimento desse adubo verde foi aos 70 DAS, quando as plantas estavam com 135,0 cm de altura. Como os adubos verdes não receberam qualquer tipo de adubação nos dois sistemas, as únicas diferenças, portanto, devem ser devidas à fertilidade natural do solo em cada local, e, sobretudo e principalmente, às distintas épocas de semeadura, que foram em fevereiro no sistema convencional e em dezembro no sistema orgânico. Cabe ressaltar que os períodos mais favoráveis para semeadura dessas duas leguminosas nas condições climáticas do estado de São Paulo são outubro a janeiro para a mucuna-anã e outubro a março para a crotalária-espectábilis.

$\mathrm{Na}$ última colheita de quiabo, no cultivo convencional em Monte Alegre do Sul, as médias de altura das plantas de mucuna-anã e de crotalária-espectábilis nos tratamentos de consórcio com uma e duas linhas desse adubo verde foram 36,8 e $36,5 \mathrm{~cm}$ e 129,6 e $126,7 \mathrm{~cm}$, res- pectivamente. Não houve problemas de competição por luz e/ou sombreamento, sobretudo pelas plantas de crotalária, porque a altura dessas plantas foi inferior à do quiabeiro. A temperatura em Monte Alegre do Sul foi decisiva para o desenvolvimento dos adubos verdes devido à época de semeadura (temperatura mínima 16,5 e máxima $28,7^{\circ} \mathrm{C}$ ), além da fertilidade do solo no sistema convencional. No cultivo orgânico, os adubos verdes foram cortados aos 83 DAS e a biomassa remanescente permaneceu na superfície do solo como cobertura morta.

Quanto à altura do quiabeiro, não houve diferença entre os tratamentos aos 81 e 110 DAS no cultivo convencional e aos 70, 100 e 180 DAS no cultivo orgânico, sendo determinados valores médios de 77,3, 118,7, 122,3, 163,6 e 231,4 $\mathrm{cm}$, respectivamente. No consórcio com uma linha de crotalária-espectábilis, aos 172 DAP, a altura média do quiabeiro no cultivo convencional $(207,0 \mathrm{~cm})$ foi maior em relação àquela do cultivo solteiro de quiabo (160,9 cm). Entretanto, a produção de quiabo não foi incrementada por este maior desenvolvimento das plantas ao final de seu ciclo.

Em relação à produtividade dos adubos verdes no consórcio com o quiabeiro, os resultados estão agronomicamente coerentes com o esperado. Ou seja, independentemente da variedade de adubo verde, as produtividades foram sempre numericamente superiores nos tratamentos com duas linhas consorciadas do que com apenas uma, à exceção da similaridade estatística de ambos com o tratamento de consórcio com uma linha de mucuna-anã. Considerando que não houve diferença entre as quantidades de massa fresca da mucuna-anã e da crotalária quando semeadas em linhas duplas na entrelinha do quiabeiro (Tabela 2), para o agricultor familiar inferiu-se como sendo mais apropriado e satisfatório o plantio consorciado com a crotalária. O manejo das plantas de crotalária foi muito mais simples e rápido do que o da mucuna-anã e o agricultor familiar pode economizar tempo para roçá-la. Isso porque, no simples ato de caminhar pela entrelinha semeada com este adubo verde, por exemplo, na colheita do quiabeiro, as plantas da crotalária são facilmente quebradas, sendo estabelecida a cobertura morta almejada. No caso da mucuna-anã, este adubo verde precisa ser roçado para a formação da cobertura morta, o que significa o emprego de mais horas de serviço nesta alternativa.

Um benefício extra a ser mencionado, embora não mensurado qualitativa e nem quantitativamente, mas apenas resultante de avaliação visual, é a supressão das plantas espontâneas nas entrelinhas dos tratamentos em consórcio, com consequente redução do número de capinas na cultura do quiabeiro consorciado. Isso foi particularmente constatado nos tratamentos com a mucuna-anã, em que se constatou, visualmente, a total cobertura da superfície do solo nas entrelinhas da hortaliça, independentemente do número de linhas semeadas desse adubo verde.

$\mathrm{Na}$ avaliação da eficiência do consórcio em relação ao cultivo solteiro do quiabeiro e dos adubos verdes mensurada por meio da relação de área equivalente (RAE) foi confirmado o beneficio dessa ferramenta no experimento realizado em São Roque. A RAE determinada no consórcio do quiabeiro com a mucuna-anã foi de 1,1 e 1,5, respectivamente, para uma e duas linhas do adubo verde nas entrelinhas. Com a crotalária-espectábilis foi possivel obter uma RAE mais adequada no consórcio com o quiabeiro, com valores de 1,4 e 1,6 , respectivamente, para uma e duas linhas do adubo verde nas entrelinhas.

Para a produção, não houve diferença estatística entre o quiabo cultivado de maneira solteira e o de forma consorciada. Porém houve diferença na produção quando variaram-se as culturas no consórcio com o quiabo, sendo observadas maiores médias com uso de crotalária (662,4 e 612,7 g planta $^{-1}$, para uma e duas linhas). Também houve diferença estatística, apenas para mucuna-anã quando variou-se o número de linhas de cultivo no consórcio, de forma que duas linhas foram mais interessantes que uma, com médias de 611,7 e 467, 6 g planta $^{-1}$, respectivamente (Tabela 2 ).

A cultura do quiabeiro no estado de São Paulo é predominantemente realizada por agricultores familiares, em áreas de menor tamanho, sem qualquer 
motivação para considerarem o adubo verde na rotação de culturas. Isso se deve à necessidade de exploração de cada metro quadrado agriculturável para obtenção de seu alimento e renda extra para sua sobrevivência. Dessa maneira, o cultivo intercalar pode se tornar uma interessante opção, aventando-se efeitos positivos tanto na produção quantitativa e qualitativa dessa hortaliça quanto em características do solo, como relatado em Wutke et al. (2010). Assim e, diante dos resultados experimentais, constatados em ambas as localidades e em épocas distintas de semeadura do quiabeiro, constatou-se viabilidade de adoção dessa prática agrícola pelo agricultor familiar, especificamente utilizando-se adubos verdes de porte ereto e baixo, como a mucuna-anã e a crotalária-espectábilis, com aumento ou mesmo manutenção do patamar produtivo do quiabeiro.

\section{REFERÊNCIAS}

ANDRADE NC; PONTE JJ. 1999. Efeito do sistema de plantio em camalhão e do consórcio com Crotalaria spectabilis no controle de Meloidogyne incognita em quiabeiro. Nematologia Brasileira 23: 11-16.

CAMARGO AMMMP; CAMARGO FP;
CAMARGO FILHO WP. 2008. Distribuição geográfica da produção de hortaliças no estado de São Paulo: participação no país, concentração regional e evolução no período 1996-2006. Informações Econômica 38: 28-35.

CECÍLIO FILHO AB; MAY A. 2002. Produtividade das culturas de alface e rabanete em função da época de estabelecimento do consórcio. Horticultura Brasileira 20: 501504.

CESAR MNZ; RIBEIRO RLD; PAULA PD; POLIDORO JC; MANERA TC; GUERRA JGM. 2007. Desempenho do pimentão em cultivo orgânico, submetido ao desbaste e consórcio. Horticultura Brasileira 25: 322326.

IBGE. 2006. Censo agropecuário: Brasil, grandes regiões e unidades da federação. Disponível em http://www.ibge.gov.br/home/ estatistica/economia/agropecuaria/censoagro/ brasil_2006/Brasil_censoagro2006.pdf. Acessado em 28 de dezembro de 2011.

KANO C; TIVELLI SW; PURQUERIO LFV; WUTKE EB. 2010. Desempenho do quiabeiro consorciado com Mucuna deeringiana e Crotalaria spectabilis na região Leste Paulista. Horticultura Brasileira 28: S1926-S1931. Disponível em http://www.abhorticultura.com. br/eventosx/trabalhos/ev 4/A2656 T4765 Comp.pdf. Acessado em 06 de janeiro de 2011.

MELO PCT. 2007. Contribuições das hortaliças subutilizadas e ou negligenciadas à gastronomia brasileira. Horticultura Brasileira 25: 1-3. Disponível em http://www.abhorticultura. com.br/eventosx/trabalhos/ev_1/PAL17.pdf. Acessado em 28 de dezembro de 2011

MONEGAT C. 1991. Plantas de cobertura do solo: características e manejo em pequenas propriedades. Chapecó: edição do autor, 337p.

RIBAS RGT; JUNQUEIRA RM; OLIVEIRA FL; GUERRA JGM; ALMEIDA DL; ALVES BJR; RIBEIRO RLD. 2003. Desempenho do quiabeiro (Abelmoschus esculentus) consorciado com Crotalaria juncea sob manejo orgânico. Agronomia 37: 80-84.

SÃO PAULO SAA/CATI/IEA. 2008. Levantamento censitário das unidades de produção agropecuária do estado de São Paulo - LUPA 2007/2008. Disponível em http://www.cati.sp.gov.br/projetolupa/index. php. Acessado em 29 de dezembro de 2011.

TIVELLI SW; PURQUERIO LFV; KANO C. 2010. Adubação verde e plantio direto em hortaliças. Revista eletrônica Pesquisa e Tecnologia 7: 1-7. Disponível em: http:// www.aptaregional.sp.gov.br/artigo.php?id artigo $=714$. Acessado em 28 de dezembro de 2011.

TRANI PE; PASSOS FA; NAKAI H. 1997. Quiabo. In: RAIJ B van; CANTARELLA H; QUAGGIO JA; FURLANI AMC (eds.). Recomendação de adubação e calagem para o estado de São Paulo. Campinas: IAC \& Fundação IAC. p.183. (Boletim Técnico 100).

WUTKE EB; AMBROSANO EJ; RAZERA LF; MEDINA PF; CARVALHO LH; KIKUTI H. (Coord.). 2007. Bancos comunitários de sementes de adubos verdes: informações técnicas. Brasília, Ministério da Agricultura, Pecuária e Abastecimento. 52p.

WUTKE EB; TRANI PE; AMBROSANO EJ; DRUGOWICH MI. 2010. Adubação Verde no Estado de São Paulo. Campinas. CATI. 89p. (Boletim Técnico CATI 249. $2^{\mathrm{a}}$ imp.) 